\title{
Research on Chinese Internet Buzzwords Translation
}

\author{
Lu Wenchan', a , Wei Ke ${ }^{2}$ \\ ${ }^{1}$ School of Journalism and Communication, Central China Normal University, Wuhan 430079, China \\ ${ }^{2}$ School of Foreign Languages, Hubei Engineering University, Xiaogan 432000, China \\ ahbludingyuan@163.com
}

Keywords: Internet buzzwords; Features; Translation; Culture

\begin{abstract}
With the development and popularity of the internet in China, the internet buzzwords have inevitably penetrated into daily life. On the one hand, the convenient access to the internet has made more people concerned about national and international hot events, while the internet buzzwords often reflect the netizens' attitudes and appeal. On the other hand, these internet buzzwords can add a humorous touch in their daily conversations. As a part of cross-cultural communication, the translation of Chinese internet buzzwords should reflect the original characteristics of Chinese culture.
\end{abstract}

\section{Introduction}

In recent years, internet buzzwords have presented a trend of rapid development and have gradually become a new force of China's internet culture. This culture has substantial content, fast spreading, and rich characteristics of the New Era. The content of internet buzzwords is capable of responding to the interest of the people. It is the people that convey their opinions to the society through the internet, and the internet becomes the mouthpiece of public opinion transmission. At the same time, network language with its sharp and humorous style can often point out the contradictions of hot issues due to the defects of society. Blog, post bar, net forum, QQ group and so on are the active sites for the use of internet buzzwords. Internet buzzwords, to a certain extent, reflect the social mood, and the internet has delivered a new way of public opinion collection. Internet buzzwords are affecting us by a unique way.

As a member of Chinese netizens, the author often joins some discussions in English on some hot issues, many Chinese internet buzzwords are translated during the process. Unfortunately, the Chinese-English translations of internet buzzwords embody a lot of mistakes due to the lack of professional knowledge and skills of the translators, which may hinder the development of Chinese internet culture and cross-cultural communication on the whole. On the basis of previous studies, In the following I would summarize the features of Chinese internet buzzwords and put forward some positive suggestions for Chinese-English translation of internet buzzwords.

\section{The overall features of Chinese internet buzzwords}

Internet buzzwords demonstrate the social diversity and enrichment. As a vocabulary phenomenon, internet buzzwords reflect people's general concerns of a certain period about some issues or things. When information technology was underdeveloped in the past, people might use some catchy ballads or mandarin language to express their feelings of dissatisfaction or opinions on something. With the advent of the internet, people began to express themselves on the internet on certain topics, giving rise to the creation of internet buzzwords, such as "woju"(narrow dwelling),"shengnyu”(leftover ladies), "kenlaozu”(elderly-devouring group or the NEET group). Although these network buzzwords are very short, they imply profound social problems. In the internet era, network buzzwords like these emerge endlessly, and English translations of these words with unique language styles are becoming increasingly popular in foreign mass media. Its impact should not be ignored. 
Internet buzzwords are created and used under the influence of social and cultural circumstances. Network buzzwords are closely linked with social reality, expression of public opinion, and cultural tradition. Popular internet buzzwords are essentially the netizens' demands and yearn for recognition or change for the better. In addition, the formation and propagation of internet buzzwords are also a process of conformity of internet users. Internet buzzwords have now almost become an indicator of public opinion.

According to the meaning, Chinese internet buzzwords can be divided into four categories. The first category is mainly connected with political and economic affairs, such as "san ge daibiao" (Three Represents), "guangpan xingdong” (Clear Plate Campaign), "fan fu” (Anti-corruption), etc. The second category includes words related to science, technology, high and new technology industry, such as "wuren jiashi" (manless driving), "dian shang” (E-Commerce), "wang gou" (online shopping), "3D dayin" (3 d printing). The third category is about environment protection and medicine, such as "PM2.5" (Particulate Matter 2.5), "Beijing lan" (Beijing blue), "yi nao" (medical trouble profiteering), etc. The fourth category is given to words on cultural, sports, recreational and mass media affairs such as "wo ye shi zuile" (I am drunk/I am speechless), "honghuang zhi li” (prehistoric powers), "lanshouxianggu” (skinny blue mushroom/ feel awful and want to cry), etc.

\section{Discussions on the translation of Chinese internet buzzwords into English}

\subsection{Free translation}

When translating Chinses internet buzzwords into English, one cannot always find equivalent words in the target language; neither can he or she use full reciprocal things to explain, due to the uniqueness of the source language and culture. Considering the great differences between Chinses and English, the translator may only need to be faithful to the original content and try to convey the cultural connotation of the words without having to represent the form and rhetoric of the original language. In this case, free translation method can be a good solution to this problem of translating Chinese internet buzzwords.

Example 1: “beiju”(cup), "luo hun”(naked wedding), “da jiangyou”(buy soy sauce)

Translations: tragedy, welding wedding, passer-by

Discussion: "Beiju" in Chinese means a container of water that can usually be translated into "cups" in English under normal circumstances. But the internet buzzword "beiju” refers to Chinese homophone for "beiju", a tragedy or an unfortunate personal encounter. For the next word "luo hun", if it is translated into naked wedding, the word may cause ambiguity. "luo hun” does not mean the wedding is naked, but it refers to a simple way of marriage. The two sides do not put house, car, and money as the necessary basis for their marriage. By the same token, the original meaning of "da jiangyou" is "on the way to buy soy sauce." But for internet buzzword "da jiangyou" means "That thing has nothing to do with me". So "passer-by" may be a more appropriate translation for "da jiangyou”.

\subsection{Literal translation}

If the Chinese internet buzzwords have the same meaning with words in English, literal translation is the best choice. The advantage of literal translation is its retaining of the original language content and form, cultural characteristics to a large extent, maximizing the barrier-free effect of cross-cultural communication.

Example 2: “Zhongguo meng”(Chinese dream), “fen qing”(angry youth), “miao sha”(killing in a second)

Translations: Chinese dream, angry youth, seckill

Discussion: "Zhongguo meng"(Chinese dream) is in accordance in terms of word-formation with "American dream"(Meiguo meng). The Chinese dream is the most appropriate translation for translating "Zhongguo meng", and it is more easily accepted and understood by foreigners. "fen qing” refers to the young people who are dissatisfied with society. The most direct and vivid 
translation might be "angry youth". This translation is conducive to the transmission of the meaning of buzzwords, and it also makes the target language closer to the source language. The term "miao sha" originally comes from computer games meaning "killing in second". When associated with online shopping, "miao sha"(seckill) refers to the quick sell out of newly-advertised goods. The translation of "miao sha" into "seckill” fully and vividly conveys the message.

\subsection{Transliteration translation}

Transliteration method is often carried out using directly the Chinese phonetic transcription (Hanyu pinyin) spellings. This method is easy, direct, and mainly used to translate the names of persons, places, buildings and commodity brands.

Example 3: “dama”(middle-aged woman/women), "guanggun”(single men or women), "tuhao"(rich people of low social status)

Translations: dama, guanggun, tuhao

Discussion: The original meaning of "dama” in Chinese means middle-aged woman/women. In recent years Chinese "dama” are known by foreigners as square dancers and shopping mall buyers when they go abroad as tourists. The original meaning of "guanggun" is unmarried man or bachelor, but now it also refers to unmarried women. So "an unmarried man" or "bachelor" cannot fully convey the meaning of "guanggun". The originally "tuhao" refers to the rich landlord or local tyrant in rural China in the past, but now the internet buzzword "tuhao" refers to people who newly become rich but of low social status. In order to preserve the cultural connotation of the source language, transliteration is adopted for the above-mentioned internet buzzword translation, directly using the Chinese phonetic transcription spellings.

\section{Conclusions}

Internet buzzword is a kind of cultural phenomenon. It is also the product of internet and information development. In order to translate internet buzzwords effectively one should not pay attention only to the differences of the two languages in question, but also to the different cultural connotations of the words. Internet buzzword is like a mirror, reflecting the progresses and problems of the society. Some internet buzzwords will settle down into our life, while other internet buzzwords will disappear. Accurate translation of the constantly changing buzzwords requires thorough understanding of the two respective languages and cultures and careful observation of the fast advancing societies. Here and there modifications may be added to certain translation method, and specific techniques may be used to cater to the concrete situation and to serve special purpose.

\section{References}

[1] Crystal, David. Language and the Internet [M]. New Cambridge: Cambridge University Press, 2001: 142-144

[2] Davis, L. Doing Culture: A Cross Cultural Communication in Action [M]. Beijing: Foreign Language Teaching and Research Press, 2001.

[3] Ungere, F \& Schmidt, H.J. An Introduction to Cognitive Linguistics[M]. Beijing: Foreign Language Teaching and Research Press, 2008.

[4] Lefebvre, A. Translation - History, Culture: A Sourcebook [M]. Shanghai: Shanghai Foreign Language Education Press, 2004.

[5] Nida, E.A. The Theory and Practice of Translation [M]. Shanghai: Shanghai Foreign Language Education Press, 2003.

[6] Jing, Mo: An Analysis of the Chinese- English Translation of Internet Hot Words and Catchphrases [J]Crazy English Teacher's Edition, 2015(3):137-140

[7] Weidong, Wang. An Exploration of the Chinese-English Translation of Network Hot Words[J]Chinese Translators Journal, 2011(1):73-77 